\title{
Teachers Preparedness on Implementation of Competence Based Curriculum in Lower Public Primary Schools in Kilifi and Nandi Counties, Kenya
}

\author{
Mary Jebii Chemagosi
}

Pwani University, Kenya

\begin{abstract}
The competency based curriculum was introduced in Kenya in 2016 as pilot study for the new curriculum but adapted in 2019 in all pre-schools and lower primary school levels. The curriculum is viewed as a panacea in solving problems of unskilled school leavers with knowledge based to practical based curriculum. The objective of the study was to establish teachers' preparedness on implementation of competence based curriculum in lower public primary schools in Kilifi and Nandi counties, Kenya. This aimed to generalize the study findings to other counties in Kenya. The study used descriptive research design. Data was collected by use of questionnaire, interview schedule and observation schedule. The sample used was 12 head teachers and 48 teachers that were purposively selected. A pilot study was conducted in two schools one from each of the two Counties to pre-test and adjust the instruments. The study made use of teachers' questionnaire, head teachers interview schedule and observation schedule to collect and analyse data from the participants. Validity was ensured by face and content validity while Split-half technique ensured instruments reliability. The quantitative and qualitative data were simultaneously collected and analysed in order to triangulate the findings of the study. The results shows that the overall model is significant $(\mathrm{F}=6.006, \mathrm{p}<0.05)$ and the coefficient also shows that teacher preparedness contributes significantly on implementation of competency based curriculum $(\beta=0.342$, $\mathrm{t}=7.985, \mathrm{p}>0.05)$. This implies that teacher preparedness significantly influence implementation of competency based curriculum and therefore the hypothesis that there is no significant difference between teachers' preparedness and implementation of competency based curriculum was rejected. The study recommended that the Ministry of education to ensure teachers are well equipped with requisite skills, knowledge and teaching and learning resources to adequately prepare teachers for competency based curriculum.
\end{abstract}

\subsection{Introduction}

Education has been described as an engine drive for social and economic advancement of any nation. Most of developed countries owe their source from technical and economic innovations. It is from the foregoing that educational reforms needs curriculum change in order to equip learners with the ever fast growing demand of higher education and job market opportunities in the $21^{\text {st }}$ century through the Competency Based Curriculum. The competency based curriculum originated from the United States of America in 1970's adopted by other English speaking countries including United Kingdom, Canada, Australia, India, New Zealand, South Africa, Nigeria, Tanzania (DeiBinger and Hellwig, 2011) and now Kenya. DeiBinger and Hellwig (2011) further observed that the middle training colleges and adult education centres produced students with insufficient learning outcomes. Based on this low education achievement the Competency Based Curriculum was introduced in most countries in order to bring a change from teacher centred approach to learner centred approach of teaching and learning process (Richard \& Rogers, 2014; Wong, 2008).

According to the Woods (2008) and World Bank (2011) teaching and learning process should have a shift from rote memorization of content knowledge to acquisition of skills, Knowledge and competencies to fit in the present modern way of life. The competence based curriculum emphasizes on learner achievement rather than mere acquisition of content based knowledge. Therefore the syllabus revision should encompass a 
paradigm shift from content-based to competence-based curriculum. This means during the learning process, the competence based curriculum should stress on development and assessment of specific areas of competencies.

Most African countries adopted the Competency Based Curriculum with view of a change from objective learning content to outcome learning approaches. This entails much emphasis on formative rather than summative evaluation. In Competency Based Curriculum, learners are to construct own knowledge during the teaching and learning process. Whereas learners are to acquire, develop, demonstrate and accomplish the actual competency, competence based curriculum requires teachers to merely act as facilitators, guider and cognitive trainer (Cheptoo, 2019). Ajibola (2008) noted that most teachers are not trained and competent enough to handle the new subjects that have been anchored in the curriculum. Amugo (2007) concur that there exists a significant relationship between the quantity and quality of teachers and secondary school curriculum in Nigerian schools. The foregoing means that the Competence Based Curriculum should develop and produce learners with requisite skills and knowledge to perform potential tasks rather than equip learners with theoretical knowledge-based curriculum.

Brazil adopted competency based curriculum in order to produce effective teachers who have knowledge of different capabilities of methodological abilities to assist learners develop their full potentials. This aimed to have a self-reliant learner job reliance and satisfaction. In India competence based curriculum was intended to prepare teachers with professional skills in methodology for social milieu of learners and develop cognitive and critical thinking. Much emphasis was put on teacher training that aim to equip teachers with content subject matter, communication skills, managerial skills and methodological competency in order to produce learners of both cognitive and non-cognitive domains.

Malaysia prepares teachers who have teaching and learning skills, knowledge and understanding, and values of teaching profession. This aim to produce creative teachers who are non-exam oriented, are passionate as professional teachers, motivate and cares for learners, possesses the subject content matter and methodological knowledge. However, lack of feedback and support on implementation of competence based curriculum in the actual classroom teaching are barriers to effective realization of the programme.

In Rwanda the lower primary learner profile of competency based curriculum includes acquisition of social skills, language skills, physical and mental abilities and community responsibilities (MOE, 2015). This requires teacher's paradigm shift from use of traditional pedagogical instruction to the use of the competence based curriculum methodological approaches.

In Tanzania, the competency based curriculum was adopted in order produce graduates with requisite skills to fit in the modern society. The teacher training institutions had to incorporate the competency based curriculum so as to assist learners with relevant skills needed for socio-economic development of the individual/nation.

In Kenya the education system has undergone three fundamental changes since independence. In 1964 Kenya adopted the 7:4:2:3 that intended to eliminate the colonial education that was considered to be segregative. In 1985 the Mackay led commission recommended and adopted the 8:4:4 system of education that aimed to eliminate the examination oriented system of education that existed in order to replace it with practical oriented and enable learner's to be self-reliant. Lastly, the present adoption of 2:6:6:3 structure designs have the following core competencies:

- communication and collaboration: learners should communicate and participate in different class activities with teachers during learning to learn:

- Learning to learn: learner's should continue develop their skills and abilities' during class activities

- Self- efficacy: continued development in acquisition of skills, participation and cooperation with others

- Creativity and imagination: appreciate individual abilities, talents and participation

The 8:4:4 was criticized as being exam oriented. The learners were to master the content, recall and apply in examination. This was in contrast to the sole aim of early identification of learner's talents and exploitation of the same. 


\subsection{Statement of the problem}

The introduction of 8.4.4 system of education in 1985 aimed to produce graduates who were self-reliant for job market and economic development. However, the system proved to be examination oriented that did not prepare learners with relevant desired skills. The introduction of competence based curriculum in 2019 is aimed at mitigating the weaknesses identified in 8.4.4 the curriculum. This calls for change in teacher preparation in all training colleges and the current servicing teachers in order to adjust to the demands of the newly introduced curriculum. However, since the competence based curriculum for primary schools was introduced, there exists no evidence in teacher training colleges and servicing teachers to have fully been prepared for competence based curriculum that is currently taught in PPI, PP2, and grades 1, 2, 3 and 4. This is to align with the demands of the new curricula. This continues to raise question of whether teachers are well equipped with requisite skills, knowledge and competency to handle learners in lower primary schools. This despite the fact that teachers are considered as engine drive for implementation of competence based curriculum. A part from the seminars that have been held across the country to sensitize teachers on the new curriculum, there is little evidence on teachers' preparedness on implementation of competence based curriculum in lower primary schools. Therefore, the present study tried to identify the gaps so as to strengthen strategies on teachers' preparedness on implementation of competence based curriculum in lower public primary schools in Kilifi and Nandi counties in Kenya.

\section{Purpose of the Study}

The study sought to investigate on teachers' preparedness on implementation of competency based curriculum in lower public primary schools in Kilifi and Nandi counties in Kenya.

\section{Hypothesis of the Study}

There is no significant difference between teachers' preparedness and implementation of competency based curriculum.

\section{Delimitation of the Study}

The participants were lower primary teachers from grade one to grade three in Kilifi and Nandi counties in order to generalize the findings of the study. These grade levels were purposively selected because competence based curriculum is actualized at these levels.

\section{Theoretical framework}

The study was premised on the model of knowledge development during teaching and learning process as advocated by Shulman (1986). The theory demands teacher's effective acquisition of pedagogical content knowledge and skills. It stipulates the relationship between teacher's subject content matter and pedagogical instruction that enable learner's acquisition of skills and knowledge during the teaching and learning. In this theory, teacher preparedness entails development and acquisition of required competencies in the implementation of competence based curriculum. The theory notes that a teacher characteristic has an influence on the teacher's instructional pedagogy, classroom management and overall teaching and learning process.

\subsection{Literature Review}

Teacher training institutions are planned to take care of education at all levels of learning. Both pre-service and in-service teacher training programmes are pivotal because they are expected to equip them with professional knowledge, skills and attitudes and communication skills in order to identify and strengthen teaching and learning needs of learners and become efficient and effective competency based curriculum implementers (UNESCO, 2010). All in all, teacher influence on any new curriculum depends entirely on the teacher preparedness. Hawes (1979) note that curriculum implementation cannot be divorced from any form of teacher training. Ornstein and Hunkins, (2004) observed that teachers have a role to influence learners performance and therefore teachers enable improved and better learning outcomes. Therefore, teachers have key role to interpret the objectives and content during curriculum implementation for successful translation into actual practice. Ugwulashi (2013) noted that teachers need enough time for planning, organizing, implementing and evaluating of school activities in order to achieve the set objectives and goals of the school.

Osifila (2004) study on correlation between physical facilities and students' academic performance established a significant relationship between adequate physical facilities; and teachers' classroom 
effectiveness and students' academic outcomes. Adeleke (2007) opines that effective implementation of the new secondary school competency based curriculum in Nigeria faces problems such as inadequate physical facilities and instructional materials, limited competent and qualified teachers, inadequate funding, and lack of teachers' motivation. Ndukwe (2002) noted that most schools in Nigeria lacked recreational and games facilities. Okpala (2006) adds that whereas most learners in Nigeria learn under shade of trees, others sit on bare floor during classroom teaching and learning process.

Ahmadi and Lukman (2015) conducted a study on issues and prospects of effective implementation of new secondary school curriculum in Nigeria. The study established that the government has prioritized in-service courses to professionally develop and involve teachers in curriculum planning and execution. Ajayi (2009) carried out a study on the relationship between adequacy of instructional materials such as books, teaching and learning aids and teachers curriculum implementation in Nigerian secondary schools. The study revealed a significant relationship between availability and efficient use of teachers' instructional materials and curriculum implementation in secondary schools.

Nwagwu (2003) noted that inadequate government funding in schools manifest in congested classrooms, inadequate laboratories, libraries and lavatories. These manifest into poor teaching and learning environment, occurrence of disciplinary problems and job dissatisfaction among the teaching staff. This leads to ineffective curriculum implementation and failure to achieve the curriculum objectives and goals.

Komba and Mwandanji (2015) conducted a study on the implementation of competence based curriculum among secondary schools in Tanzanian. The study revealed that $86 \%$ of the teachers did not have the prior knowledge of competence based curriculum. The researcher further observed that $78 \%$ of the teacher's lesson plans did not reflect the actual qualities of recommended competence based curriculum compliance. It was also noted that student's involvement in classroom activities by the teachers was ineffective.

Paulo (2014) further conducted a study on teachers training on preparedness on implementation of competent based curriculum in secondary schools in Tanzania. The study purposively sampled 16 preservice teachers from the University of Dar es Salaam. The study used interview guide and observation checklist. The study revealed that the classroom teaching and assessment modes of teachers did not comply with the competence based curriculum. It was also noted that trained teachers continue to use the traditional mode of teacher centred approach as opposed to competence based curriculum that demands the learner centred approach. The study recommended that all the universities in Tanzania introduce the competence based curriculum.

Ondimu (2018) conducted a study on teachers' preparedness for implementation of competence based curriculum in private pre-schools in Dagoretti North Sub County, Nairobi County in Kenya. The study had a sample of 96 pre-school teachers and 12 head teachers selected through simple random technique. Data was collective by use of teachers' questionnaire and head teachers interview guide. The study established that lack of Information Communication Technology (ICT) competency among teachers, inadequate instructional materials, and high teacher: pupil ratio and lack of parental support hinders smooth implementation of competency based curriculum. The study recommended the Kenya Institute of Curriculum Development to intensify teacher in-service courses to equip teachers with ICT skills and have a positive attitude towards implementation of competence based curriculum. The study was limited in methodology because it was only conducted in one Sub County in contrast to the present study that was conducted in two Counties.

Waweru (2018) carried out a study on influence of teacher preparedness on implementation of competency based curriculum in public primary schools in Nyandarua North Sub County, Kenya. The study established that teachers need more training because the in-service progammes was inefficient for implementation of competence based curriculum. It was further revealed that inadequate instructional materials, over emphasis on lesson planning and mode of learner's assessment were still wanting for effective implementation of competence based curriculum.

According to Joint ILO/UNESCO report (2009) most developing nations in the world face problem of overcrowding in classrooms that undermine teacher's competency in curriculum delivery of quality education. A small class size enables teachers to be competent enough in classroom delivery and pupil's better performance. Teachers are confronted with immense workloads and high teacher: pupil ratio that 
affects their effectiveness in daily teaching and learning process. A study by Sichambo (2011) on impact of burnout on secondary school teachers in Bungoma North district established that responsibilities of dealing with large classes, more paper work, attending to remedial classes, classroom teaching, being class teachers and extra curriculum activities are burnouts that slowed down teachers competency in effective teaching and learning. Watitwa (2010) recommended for more employment of teachers in order to reduce teacher's workload and allow teachers to thoroughly prepare for practical daily lessons. Odumbe, Simatwa and Ayodo (2015) study on factors affecting students' performance in day secondary schools in Migori district, Kenya noted that reduced teacher-pupil ratio improves students' learning outcome. In addition, Mayeku (2009) noted that understaffing which cause high teacher: pupil ratio in most schools made teachers incompetent in curriculum delivery.

Rop and Momanyi (2019) conducted a study on teacher preparedness for the implementation of competency based curriculum in lower primary schools in Bomet East Sub-County, Kenya. The study concluded that teachers are ill-prepared for efficient competency in assessment of learner's performance. The study recommended to Kenya Institute of Curriculum Development and the ministry of education to mount adequate training sessions to bridge capacity gaps identified in methodology, evaluation and preparation of teachers professional documents.

\subsection{Methodology of the Study}

\subsection{Study design}

The study employed descriptive survey design. The design enabled to collect both qualitative and quantitative in-depth information on teacher's perception and attitudes on their preparedness on implementation of competency based curriculum.

\subsection{Study Locale}

The study was conducted in lower public primary schools in Kilifi and Nandi counties, Kenya. The national report on pilot study (2018) on competency based curriculum in PPI, PP2, and grades one levels had identified gaps such as; teachers lack of adequate time for teaching and learning, non-compliance in digital devices competency, large classes, inadequate physical and instructional resources, inadequate parental involvement, handling learners who exceed expectations, change from inquiry based approach, and lack of clear policy on assessment rubrics among others. The researcher purposively selected the two counties that are 800 kilometers far apart because of the diverse geographical, cultural and social-economic differences in order to generalize the findings of the study to other counties in Kenya.

\subsection{Study participants}

The sample consisted of 48 teachers (24 in Kilifi County and 24 in Nandi County and 12 head teachers (6 from Kilifi County and 6 from Nandi County) that were purposively selected because of the vast geographical terrain of the two Counties.

\subsection{Study Instruments}

\subsubsection{Questionnaire}

The study utilized teacher's questionnaire to collect data from teachers because they are the actual implementers of competence based curriculum. The self-designed structured questionnaire had both closed and open-ended questions. They questionnaire had similar standardized set items for participants responses. The questions were based on a five point Likert scale listed and scored as SD (1), D (2), N (3), A (4) and SA (5). The questionnaire were serially numbered, coded and scored to ease data identification and analysis. The questionnaire aimed at gathering information in a quick span of time over a large geographical area on a sparsely sample study.

\subsubsection{Interview guide}

The interview guide was a one to one face oral conversation to gather in-depth and rich information from head teacher's perception on teacher's implementation of competence based curriculum. This was premised on the fact that they are charged with the core responsibility to supervise and oversee the policy implementation of competence based curriculum in their various schools. 


\subsubsection{Observation guide}

The observation guide was used to observe the actual teacher's classroom pedagogy in order to strengthen the questionnaire and interview guide study findings on teacher's preparedness on implementation of competence based curriculum.

\subsection{Pilot Study}

A pilot study was conducted in two schools; one from each of the two Counties to pre-test and adjust the study instruments accordingly. The pilot participants were 2 head teachers who were interviewed and 4 teachers who provided their responses on the self-designed structured questionnaire. The errors identified necessitated the final adjustments and revision of the study instruments before the actual study.

\subsection{Validity of the instruments}

Face validity ensured the facial appearance of the instruments whereas content validity ensured that all the variables contained in the study were captured in the instruments.

\section{Reliability of the instruments}

Split-half technique that was divided in two equal half's was used to test for instruments reliability. The technique had the advantage of saving time and was administered once on the study participants. The results of the two equal test items were collapsed into a single test using the Pearson's product moment co-efficient. As postulated by Mugenda and Mugenda (2003) a co-relation co-efficient of $0.7(70 \%)$ is deemed most appropriate for the actual study. A correlation coefficient of 0.76 for the teacher's questionnaire and 0.81 for head teachers interview guide was obtained and used for this study.

\subsection{Data Analysis}

The quantitative data was analysed by use of descriptive statistics that was produced in frequencies and percentages, and presented in tables. The inferential statistics ANOVA was used to indicate the relationship between items of independent variable (teacher's preparedness) and dependent variable (implementation of competence based curriculum). The content analysis of qualitative data was presented in narrative form. The quantitative and qualitative data were simultaneously analysed for triangulation of the findings of the study.

\subsection{Findings and Discussion}

The objective sought to determine teachers preparedness on implementation of competency based curriculum. In this study, strongly disagree (SD) and disagree (D) are collapsed into disagree whereas agree (A) and strongly agree (SA) means agree. Neutral was treated as neither agrees nor disagrees because of inability to provide appropriate response. The teacher's response is indicated in Table 1.

\begin{tabular}{|c|c|c|c|c|c|c|c|c|c|c|}
\hline \multirow[t]{2}{*}{ Competency } & \multicolumn{2}{|l|}{ SD } & \multicolumn{2}{|l|}{$\mathbf{D}$} & \multicolumn{2}{|c|}{$\mathbf{N}$} & \multicolumn{2}{|l|}{$\mathbf{A}$} & \multicolumn{2}{|c|}{$\mathbf{S A}$} \\
\hline & $\mathrm{f}$ & $\%$ & $\mathrm{f}$ & $\%$ & $\mathrm{f}$ & $\%$ & $\mathrm{f}$ & $\%$ & $\mathrm{f}$ & $\%$ \\
\hline Subject content matter & 6 & 12.5 & 16 & 33.3 & 2 & 4.2 & 16 & 33.3 & 8 & 16.7 \\
\hline Availability of ICT equipment & 18 & 37.5 & 15 & 31.3 & 6 & 12.5 & 4 & 8.3 & 5 & 10.4 \\
\hline Instructional use of ICT & 27 & 56.3 & 9 & 18.7 & 0 & 0.0 & 6 & 12.5 & 6 & 12.5 \\
\hline $\begin{array}{l}\text { Acquisition of communication } \\
\text { skills }\end{array}$ & 10 & 20.8 & 15 & 31.3 & 2 & 4.2 & 13 & 27.0 & 8 & 16.7 \\
\hline Involvement in curriculum design & 40 & 83.3 & 5 & 10.4 & 3 & 6.3 & 0 & 0.0 & 0 & 0.0 \\
\hline $\begin{array}{l}\text { Effectiveness of pre-service } \\
\text { courses }\end{array}$ & 10 & 20.8 & 13 & 27.1 & 3 & 6.3 & 12 & 25.0 & 10 & 20.8 \\
\hline Effectiveness of in-service courses & 14 & 29.1 & 11 & 23.0 & 2 & 4.2 & 13 & 27.0 & 8 & 16.7 \\
\hline $\begin{array}{l}\text { Classroom management of } \\
\text { pupil's discipline }\end{array}$ & 11 & 23.0 & 14 & 29.1 & 1 & 2.1 & 13 & 27.0 & 9 & 18.8 \\
\hline Adequacy of physical facilities & 9 & 18.7 & 13 & 27.1 & 3 & 6.3 & 18 & 37.5 & 5 & 10.4 \\
\hline Use of physical facilities & 10 & 20.8 & 19 & 39.6 & 1 & 2.1 & 13 & 27.0 & 5 & 10.4 \\
\hline
\end{tabular}




\begin{tabular}{|l|l|l|l|l|l|l|l|l|l|l|}
\hline $\begin{array}{l}\text { Adequacy of instructional } \\
\text { materials }\end{array}$ & 10 & 20.8 & 15 & 31.3 & 8 & 16.7 & 8 & 16.7 & 7 & 14.6 \\
\hline Use of instructional materials & 11 & 23.0 & 9 & 18.7 & 5 & 10.4 & 10 & 20.8 & 13 & 27.1 \\
\hline $\begin{array}{l}\text { Management of time for } \\
\text { preparation of professional } \\
\text { records }\end{array}$ & 6 & 12.5 & 25 & 52.0 & 8 & 16.7 & 5 & 10.4 & 4 & 8.3 \\
\hline $\begin{array}{l}\text { Administration of pupils } \\
\text { assessment }\end{array}$ & 14 & 29.1 & 10 & 20.8 & 3 & 6.3 & 13 & 27.1 & 8 & 16.7 \\
\hline Teacher's extra workload & 9 & 18.8 & 17 & 35.4 & 4 & 8.3 & 8 & 16.7 & 10 & 20.8 \\
\hline The teacher: pupil ratio & 17 & 35.4 & 20 & 41.7 & 0 & 0.0 & 6 & 12.5 & 5 & 10.4 \\
\hline & & & & & & & & & & \\
\hline
\end{tabular}

Table 1 indicates that a majority of teachers $24(50 \%)$ agree that they are competent enough in the subject content matter as demands the competency based curriculum. Only $22(45.5 \%)$ disagree that they do not possess the requisite competency as required by competency based curriculum. This was corroborated by an excerpt from one of the head teacher who concur that "most teachers have been provided with relevant books that contains the subject content matter from the government, HT, 8." It was observed that the relevant instructional materials were available in most schools. This implies that teachers have the requisite content matter for effective implementation of competency based curriculum. The finding concurs with those of the Indian government which aim to train and equip teachers with content subject matter, communication skills, managerial skills and methodological competency in order to produce learners of both cognitive and non-cognitive domains. The finding further corroborates with that of DeiBinger and Hellwig (2011) who observed that the middle training colleges and adult education centres produced students with poor learning outcomes.

It is established from the table that whereas a minority of the teachers $9(18.7 \%)$ agree that the ICT equipment is available in schools, a majority of them $33(68.8 \%)$ disagree with the statement. One of the head teacher said that "We only have the tablets that were provided by the government but most of them are not functional and lack storage facilities, HT, 4. The researcher established that apart from dysfunctional tablets, there isn't any other logical ICT equipment that is schools. This tells that teachers cannot be competent enough in disseminating ICT skills and knowledge to the learners. The findings agree with the finding of Ondimu (2018) who established that lack of Information Communication Technology (ICT) competency among teachers hinders smooth implementation of competency based curriculum.

The table shows that a majority of the teachers $36(75 \%)$ are not competent enough in the use of ICT instructional teaching and learning. Only $12(25 \%)$ of the teachers are competent enough in the use of ICT instructional teaching and learning. An observation indicated that teachers did not use ICT devices during teaching and learning processes. One of the head teacher said "My teachers cannot use ICT devices during teaching because they have not undergone any formal training, HT, 6." This is evident that teachers are not competent enough in the use of ICT in order to change from old methodological approach to modern implementation of competence based curriculum. This is in line with Ondimu (2018) whose study recommended to the Kenya Institute of Curriculum Development (KICD) to intensify teacher in-service courses to equip teachers with ICT skills and have a positive attitude towards implementation of competence based curriculum.

A majority of teachers $45(93.7 \%)$ indicated that they are not involved in the curriculum design. Only a marginal percentage $3(6.3 \%)$ were unable to provide an appropriate response. One of the head teacher noted that "Our role is only limited to the implementation of the new government policy on competency based curriculum, HT, 9." This shows that although teachers are key in the implementation of competency based curriculum, most teachers are not active participants in the design and formulation of curriculum change. Teacher involvement in curriculum change may lead to immediate identification and mitigation of its weakness in order to suit its appropriateness. The findings concurs with Cheptoo (2019) who noted that whereas learners are to acquire, develop, demonstrate and accomplish the actual competency, competence 
based curriculum requires teachers to merely act as facilitators, guider and cognitive trainer (Cheptoo, 2019).

It is observed from the table that a majority of the teachers $23(47.9 \%)$ agree that pre-service training from college was not adequate to be competent enough to implement the competency based curriculum. Only 22 (45.8\%) agree that the pre-service course enable them to be competent in implementation of competency based curriculum. Some head teachers that were interviewed also noted that there is a gap between the contents of pre-service teacher training college and competency based curriculum. This means that teacher training colleges should offer training that align with the current competency based curriculum. This confirms the findings of DeiBinger and Hellwig (2011) who observed that the middle training colleges and adult education centres produced students (teachers) with low learning outcomes.

The table shows that most teachers $25(52.1 \%)$ agree that the in-service courses, seminars and conferences that have been mounted are not adequate enough to equip them with needed competence to implement the competence based curriculum. However, $21(43.7 \%)$ of the teachers agree that in-service courses, seminars and conference equips them with requisite skills and knowledge to implement the competence based curriculum. One of the head teachers agrees with the findings stating that "When competence based curriculum was introduced, the ministry of education mounted in-service courses to update teachers on the new curriculum. This has enabled some teachers to be conversant with the contents of the competence based curriculum, HT, 12." This implies that the government should intensify teacher in-service courses, seminars and conferences for professional development. The teacher continuous capacity development is essential for job competence. Additionally, in-service courses prepare and equip teachers with professional growth to acquaint with present instructional technology and innovations as contained in competence based curriculum. Ornstein and Hunkins, (2004) concur that teachers have a role to influence learners performance and therefore teachers enable improved and better learning outcomes.

The table indicate that a majority of teachers $25(52.1 \%)$ agree that they do not possess enough competence in classroom management of discipline. This is opposed to another percentage of teachers $21(45.8 \%)$ who agree that they are competent enough in classroom management of discipline. The researcher observed that most teachers were unable to manage classroom discipline. It was observed that pupils went out and came in class at will, had frequent noise making in class and had less concentration during teaching and learning. One of the head teachers said "Most of my classrooms are overcrowded because of high enrollment coupled with few classrooms making it impossible for teachers to have effective class control and be competent enough to implement the competence based curriculum, HT, 1." The findings are consistence with Nwagwu (2003) who noted that inadequate government funding in schools manifest in congested classrooms, inadequate laboratories, libraries and lavatories that also manifest into poor teaching and learning environment, occurrence of disciplinary problems and job dissatisfaction among the teaching staff.

The table shows that a majority of teachers $22(45.8 \%)$ agreed that their schools do not have adequate physical facilities to effectively implement the competence based curriculum. Another large number of teachers $23(47.9 \%)$ agree that schools have adequate physical facilities to effectively implement the competence based curriculum. An excerpt from HT, 11 said "My school does not have adequate classrooms that hamper teacher's competence in implementation of competence based curriculum. The size of classrooms cannot accommodate more than 50 pupils. Some have leaking roofs, rough floors, un-plastered walls and broken shutters." It was observed that most schools lacked adequate physical facilities to enable teachers to be competent in implementation of competence based curriculum. The findings concur with Osifila (2004) whose study established a significant relationship between adequate physical facilities; and teachers' classroom effectiveness and students' academic outcomes.

The table shows that most teachers $29(60.4 \%)$ do not adequate use physical facilities in order to efficiently implement competence based curriculum. Only 18 (37.4\%) of the teachers agree that they have adequate physical facilities that enable them to be competent enough in implementation of competence based curriculum. Head teacher 10, noted that "My school does not have adequate physical facilities such as play grounds, spacious classrooms and library to make teachers identify and nurture learner's abilities and talents." The researcher observed that most schools lack play fields and other physical facilities to enable teachers to effectively implement competence based curriculum. The availability and adequacy of playing grounds can necessitates teacher's competency in identifying and nurturing pupil's talents such as ball 
games, athletics, subjects' performance and swimming. Spacious classrooms and well-designed furniture enables pupils sitting comfortable, free pupil-teacher classroom interaction and allow teachers attend to pupils with a variety of learning abilities such as artists and indoor games. This concurs with Brazil who adopted the competency based curriculum in order to produce effective teachers who have knowledge of different capabilities of methodological capabilities to assist learners develop their full potentials of selfreliant and self-satisfaction.

The table show that most teachers $25(54.8 \%)$ were in agreement that their schools do not have adequate instructional materials. Another number of teachers $15(31.3 \%)$ agree that their schools have adequate instructional materials. Only $8(16.7 \%)$ were undecided. It was observed that whereas some schools had adequate instructional materials others had minimal instructional materials. It was further observed that most pupils carried their books in their hands and unsecured bags. One of the excerpt from a head teacher noted that "Most of the instructional materials brought by the government are insufficient due to theft, careless handling by learners, and lack of proper storage facilities. Besides, there is no clear policy on maintenance and replacement guidelines provided by the government. In addition, most of the instructional materials come from different publishers and authors hence lack consistency, Head teacher, 5)." This implies that whereas inadequate instructional materials hampers effective teacher competency, adequate instructional materials enable efficient teacher competency in the implementation of competence based curriculum. Teachers' use of a variety of instructional materials during teaching and learning process enhance effective implementation and achievement of learners' competence based curriculum. The use of a variety of instructional materials befits individual learner's differences in regard to his/her ability and competencies. The teachers of a variety of instructional materials are to create an all-inclusive and interactive environment with available resources that makes a difference. The findings concur with Ajayi (2009) who noted a significant relationship between availability and efficient use of teachers' instructional materials and curriculum implementation in secondary schools.

It was established from the table that whereas a majority of the teachers $23(47.9 \%)$ were competent in the use of instructional materials during teaching and learning 20 (41.7\%) were not competent enough. It was observed that most teachers ignored the use of instructional materials. Most classrooms did not have wall maps, pictures, flash cards, counters and nature corners. In some schools pupils were mere listeners to the teacher other than taking an active role during teaching and learning. One of the head teacher noted "Most of the instructional materials are exposed to theft due to lack of storage facilities and maintenance, Head teacher 7." Lack of teacher's competency in the use of instructional materials during teaching and learning cannot enable pupils to acquire the desired skills and subject content matter needed in competence based curriculum. Teachers who are competent by use of instructional materials makes learning pupil- centred by actively involving them in teaching and learning. This is in contrast to Adeleke (2007) and Ondimu (2018) who opines that effective implementation of competency based curriculum in schools faces problems such as inefficiency in use of instructional materials.

The table established that a majority of teachers $31(67.5 \%)$ disagree that they did not have adequate management of time while $9(18.7 \%)$ agreed that they had adequate management of time to implement the newly competency based curriculum. The study observed that time allocated for teachers preparation of professional records was not enough. Some teachers taught without thorough preparation of lesson plans. This concurred with head teacher 3 who noted that "Teachers daily preparation of professional records is affected by lack of time for effective teaching, marking, recording compiling and reporting of pupils progress work." Lack of adequate time generally affects efficient teachers' implementation of competency based curriculum. This agrees with Ugwulashi (2013) who noted that teachers need enough time for planning, organizing, implementing and evaluating of school activities in order to achieve the set objectives and goals of the school.

The table indicate that a majority of teachers $24(50.0 \%)$ disagree that there were competent in administration of pupils assessment. Another percentage $21(37.5 \%)$ agree that they are competent enough in administration of pupils assessment. One of the head teacher noted that "Teachers are not well conversant on how to effectively assess large classes within the limited time and resources available, HT 3". The change from assessment of tests to the use of rubrics is a concept that requires small class size. The findings 
are consistence with Paulo (2014) who revealed that the classroom teaching and assessment modes of teachers did not comply with the competence based curriculum.

The table indicate that a majority of teacher $26(54.2 \%)$ disagree that their workload enable them to be competent enough to implement the competence based curriculum. Another percentage 11 (22.9\%) agree that their workload do not affect their competence base curriculum. It was further observed that a part from being a classroom teacher, teachers have extra responsibilities such as; head of subjects panels, class teachers, sports, clubs, preparing professional records, attending to parents, marking and recording pupil's assessment rubrics. This work load slows down teachers competency in implementation of competence based curriculum. The findings concur with Sichambo (2011) who noted that teachers responsibilities of dealing with large classes, more paper work, attending to remedial classes, classroom teaching, being class teachers and extra curriculum activities are burnouts that slowed down teachers competency in effective teaching and learning.

The analysis of data established that $37(77.1 \%)$ disagree that the high teacher: pupil ratio allows them to efficiently implement the competence based curriculum. Only a percentage of $11(22.9 \%)$ agree that the teacher: pupil ratio allows them to efficiently implement the competence based curriculum. One of the head teachers noted that "My class size is large that it becomes difficult for teachers to attend to each child's individual's differences, Head teacher, 2). Another head teacher said "Teachers attend to about 20-30 pupils in a class. They are able to assist every child, Head teacher, 1 "). It was observed that some classes had up to 80 pupils in class against one teacher while others had 15 to 40 pupils. A small is easy to manage unlike a large class which does not allow free interaction and assistance between the teacher and pupils. The finding is consistence with Mayeku (2009) who noted that understaffing which cause high teacher: pupil ratio in most schools made teachers incompetent in curriculum delivery.

\subsection{Study findings}

\subsection{Hypothesis Testing}

The study determined how teachers' preparedness influence implementation of competency based curriculum in lower public primary schools in Kilifi and Nandi counties in Kenya through a hypothesis that H01: There is no significant difference between teachers' preparedness and implementation of competency based curriculum. The results in the model summary show that $\mathrm{R}=.337$ suggesting that there exists a moderate relationship between teachers' preparedness and implementation of competency based curriculum. Coefficient of determination R2=.113 implies that teacher preparedness influence implementation of competency based curriculum by $11.3 \%$. This is significant since p-value $<0.05$ at $95 \%$ confidence level.

The results shows that the overall model is significant $(\mathrm{F}=6.006, \mathrm{p}<0.05)$ and the coefficient also shows that teacher preparedness contributes significantly on implementation of competency based curriculum $(\beta=0.342$, $\mathrm{t}=7.985, \mathrm{p}>0.05)$. This implies that teacher preparedness significantly influence implementation of competency based curriculum and therefore the hypothesis that there is no significant difference between teachers' preparedness and implementation of competency based curriculum was rejected.

Table 2: Effect of Teachers' Preparedness on Implementation of Competency Based Curriculum

\begin{tabular}{|c|c|c|c|c|c|c|c|}
\hline \multicolumn{8}{|c|}{ Model Summary } \\
\hline Model & $\mathrm{R}$ & R Square & \multicolumn{3}{|c|}{ Adjusted R Square } & \multicolumn{2}{|c|}{ Std. Error of the Estimate } \\
\hline 1 & $.337^{\mathrm{a}}$ & .113 & \multicolumn{3}{|c|}{.112} & \multicolumn{2}{|c|}{69669} \\
\hline \multicolumn{8}{|c|}{ a. Predictors: (Constant), Teacher preparedness } \\
\hline \multicolumn{8}{|c|}{ ANOVA $^{a}$} \\
\hline \multicolumn{2}{|l|}{ Model } & \multicolumn{2}{|c|}{$\begin{array}{l}\text { Sum of } \\
\text { Squares }\end{array}$} & $\mathrm{df}$ & Mean Square & $\mathrm{F}$ & Sig. \\
\hline \multirow[t]{3}{*}{1} & Regression & \multicolumn{2}{|c|}{30.949} & 1 & 30.949 & 6.006 & $.000^{\mathrm{b}}$ \\
\hline & Residual & \multicolumn{2}{|c|}{242.200} & 47 & 5.153 & & \\
\hline & Total & \multicolumn{2}{|c|}{273.149} & 48 & & & \\
\hline
\end{tabular}




\begin{tabular}{|c|c|c|c|c|c|c|}
\hline \multicolumn{7}{|c|}{ Coefficients $^{\mathrm{a}}$} \\
\hline \multirow{2}{*}{\multicolumn{2}{|c|}{ Model }} & \multicolumn{2}{|c|}{$\begin{array}{l}\text { Unstandardized } \\
\text { Coefficients }\end{array}$} & $\begin{array}{l}\text { Standardized } \\
\text { Coefficients }\end{array}$ & \multirow[t]{2}{*}{$\mathrm{t}$} & \multirow[t]{2}{*}{ Sig. } \\
\hline & & B & $\begin{array}{l}\text { Std. } \\
\text { Error }\end{array}$ & Beta & & \\
\hline \multirow[t]{2}{*}{1} & $($ Constant $)$ & 2.820 & .141 & & 19.977 & .000 \\
\hline & $\begin{array}{l}\text { Teacher } \\
\text { preparedness }\end{array}$ & .342 & .043 & .337 & 7.985 & .000 \\
\hline
\end{tabular}

\subsection{Recommendations}

The teacher training colleges and in-service courses should be reinforced to incorporate the competency based curriculum. The Ministry of Education should provide adequate infrastructure and teaching and learning resources to improve learners' abilities and talents. The Teachers Service Commission should improve staffing in schools to enable teachers implement competency based curriculum and learners educational outcomes.

\section{References}

[1.] Adeleke, M.H. (2006). An Appraisal of Curriculum Implementation in Nigeria, Lagos: Macus Publication

[2.] Ahmadi, A., A. \& Lukman, A. A (2015). Issues and prospects of effective implementation of new secondary school curriculum in Nigeria. Journal of Education and Practice 6 (34) pp. 29-39.

[3.] Ajayi, S.N. (2009). Evaluation of Nigeria's Educational Goals, Lagos: Memphis Publishers

[4.] Ajibola, M.A. (2008). Innovations and Curriculum Implementation for Basic Education in

Nigeria: Policy Priorities and Challenges of Practices and Implementation, Research Journal of International Studies. Issue 8 (November, 2008) pp 51-58.

[5.] Cheptoo, R. (2019). The "Africanized" Competency-Based Curriculum: The Twenty-First Century Strides. International Journal of Education Volume 7 (4) pp. 46-51.

[6.] Hawes, M. (1979). curriculum and reality in African primary schools. Harlow: Longman press.

[7.] Joint ILO/UNESCO Committee of Experts on the Application of the Recommendations concerning Teaching Personnel (CEART), Report of the Tenth session held in Paris, 28 September -2 October 2009.

[8.] Mayeku, B. (2009). Policy Guidelines and Challenges in Quality Assurance in Distance Learning Programmes in Kenyan Public Universities. An unpublished M.ED Thesis: Maseno University.

[9.] Ndukwe P.N. (2002): School and teacher factors, as determinants of classroom material resources utilization in pre-primary schools in Lagos State. Unpublished Ph.D Thesis, University of Ibadan.

[10.] Nwachuku, V. C. (2005). Issues of standards and sustainability of quality education. A paper delivered to the seminar of the all Nigeria conference of principals of secondary school, Abia State branch at kolping conference Centre, Umuahia on 20th September, 2005.

[11.] Odumbe A.G., Simatwa E.M.W., Ayodo T.M.O. (2015). Factors Influencing Student Academic Performance in Day- Secondary Schools in Migori District, Kenya. A Case Study of Migori Sub county. Greener Journal of Educational Research. Vol. 5 (3): 078-097.

[12.] Ornstein, A. C. \& Hunkins, F. P. (2004). Curriculum foundations, principle and issues. Washington, D.C: Pearson Education Inc.

[13.] Ondimu, S, M. (2015). Teachers preparedness for implementation of Competency Based Curriculum in private pre-schools in Dagoretti North Sub County, Nairobi County, Kenya, (Unpublished master's thesis) University of Nairobi, Kenya.

[14.] Okpala P. (2000). Researching learning outcomes at the basic education level in Nigeria. Inaugural lecture University of Nigeria.

[15.] Osifila, G. I. (2004). Provision and management of physical plants as correlates of academic performance in Lagos State public secondary schools. Unpublished M.Ed Dissertation, University of Lagos. 
[16.] Paulo, A. (2014) Pre-Service Teacher's Preparedness to Implement Competence-Based Curriculum in Secondary Schools in Tanzania. International Journal of Education and Research Vol. 2 No. 7 PP. 219-230

[17.] Republic of Rwanda (2015). Ministry of Education, Competency Based Curriculum. Summary of Curriculum Framework Pre-Primary to Upper Secondary.

[18.] Richards, J. \& Rodgers, T. (2014). Approaches and Methods in Language Teaching 3rded. New York: Cambridge University Press.

[19.] Rop, P.K \& Momanyi, J.M. (2019) Teacher Preparedness for the Implementation of Competency Based Curriculum in Kenya: A Survey of Early Grade Primary School Teachers' in Bomet East SubCounty. The Cradle of Knowledge: African Journal of Educational and Social Science Research Volume 7 No.1, pp. 10-15.

[20.] Sichambo, N.M. (2011). Impact of Burnout on Secondary School Teachers' Performance: A case of Bungoma North District. An unpublished M.ED Thesis: MMUST.

[21.] Ugwulashi, C.S. (2013) Time management: essential tool for teaching and learning improvement in challenging resource period in Nigeria educational research international 1 (2) pp. 61-68

[22.] UNESCO. (2010). World data on education: International bureau of education. Paris:

[23.] Watitwa, P. (2010). An Investigation of Student Related Factors that Affect Achievement in Secondary School Biology Practicals in Teso District, Kenya. An unpublished MSC Thesis: Masinde Muliro University of Science and Technology.

[24.] Waweru, J. W. (2018) Influence of teacher preparedness on implementation of competency based curriculum in public primary schools in Nyandarua North Sub County, Kenya. (Unpublished master's thesis), University of Nairobi, Kenya.

[25.] Wong R.M.H. (2007). Competency-Based English Teaching and learning: Investigation Pre-Service teachers of Chinise's learning Experiences. pp 179-198. Hong Kong Institute of Education.

[26.] Wolf, A. (2001). Competence based assessments. The British Journal of General Practice, 55(515), 461-467.

[27.] Woods, E. (2008). Tanzania case study. In UNESCO country profile commissioned for EFA global monitoring report 2008: Education for all by 2015, will we make it? Paris: UESCO.

[28.] World Bank. (2011). A regional exploration of pathways toward harmonization of mathematics and science curriculum in the East African Community. Discussion paper. Washington DC: World Bank. 